\title{
Effects of mutual learning in physical education to improve health indicators of Ukrainian students
}

\author{
Bodnar I. ${ }^{1 \mathrm{ABCD}}$, Pavlova Iu. ${ }^{1 \mathrm{ABCD}}$, Dukh T. ${ }^{2 \mathrm{ABCD}}$, Wąsik J. ${ }^{3 \mathrm{ABCD}}$, Mosler D. ${ }^{3 \mathrm{ABCD}}$, Svyshch Y. ${ }^{2 \mathrm{ABCD}}$ \\ ${ }^{1}$ Theory and Methods of Physical Culture Department, Lviv State University of Physical Culture, Ukraine \\ ${ }^{2}$ Athletics Department, Lviv State University of Physical Culture, Ukraine \\ ${ }^{3}$ Institute of Physical Education, Tourism and Physiotherapy, Jan Dtugosz University in Czestochowa, Poland
}

Authors' Contribution: A - Study design; B - Data collection; C - Statistical analysis; D - Manuscript Preparation; E - Funds Collection.

\begin{abstract}
Purpose: $\quad$ The problem of research and increasing of motor activity modes remains relevant, since motor activity is one of the main factors determining health and the level of physical condition of population. The aim of study was to analyze the impact of the mutual learning program of physical education for improvement the physical and mental fitness of students in Ukraine.

Material: $\quad$ Four groups were used for the survey: 2 experimental groups (male, $n=31$; female, $n=33$ ), which received 64 lessons of physical education, which included intra-subgroup interaction, changing of students, and control of knowledge and skills of each other, and 2 control groups (male, $n=32$; female, $n=31$ ), which received a traditional physical education lessons. Assessment of the somatic health (Ketle index, Robinson index, lifetime index, strength index) and physical preparadness (running tests, trunk from the lying position, throw of a medball). Efficiency of processing, speed of figuring out the work and mental stability were determined using Schultz-Platonov tables.

Results: $\quad$ The results suggest about an increase in the functional capacity of cardiovascular and respiratory system among male and female of experimental group. The growth of the physical fitness results was set in lifting the trunk from the lying position to the sitting and throw of medball. After the experiment, positive changes in cognitive parameters were observed in female and male of experimental group. Among control group students, the results were significantly stable.

Conclusions: The results suggest that program increased the level of physical and mental fitness of students of both gender and had a significant impact on the indicators of cardiovascular system.

Keywords: physical education, students, mutual learning, health.
\end{abstract}

\section{Introduction}

Preserving and improving of population health, prolonging the period of active healthy life, reducing premature mortality and increasing the average life expectancy are recognized among the priority tasks. The current state of health of Ukrainian population is formed under the influence of a number of factors, namely: biological, socio-economic, environmental and lifestyle factors and is characterized by a combination of pathologies with varying severity and prevalence [1]. The problem of research and increasing of motor activity modes remains relevant, since motor activity is one of the main factors determining health and the level of physical condition of population $[2,3]$. The only way out is to increase the daily motor activity and to include special aerobic exercises of moderate intensity [4].

The formation of a new ideology and a culture of health promotion of young people appears to be a challenge. Unless the solution to this problem is found, society can suffer quite noticeable and irreversible losses in human resources, which will undoubtedly negatively affect the productive infrastructure, well-being and quality of life [5]. The analysis of this problem is an urgent task of modern pedagogics and teaching practice, because health belongs to prior human values [6].

\footnotetext{
○ Bodnar I., Pavlova lu., Dukh T., Wąsik J., Mosler D., Svyshch Y., 2019 doi:10.15561/20755279.2019.0503
}

The high level of academic load of students, which is over 36-40 hours per week, its uneven distribution during the day and week, the disordered organization of extracurricular activities - all this negatively affects the efficiency of students' organism [7, 8]. Study [9] showed that $15-20 \%$ of the Ukrainian students have some deviations in their health.

The need for an additional muscular activity becomes more required [10]. Specialists [11-13] emphasize that in order to improve the health of students of higher educational institutions, it is, first of all, necessary to use means of physical culture, aimed at improving the development of motor qualities. However, the health effect of exercising requires a clear and regulated organizational system and regular monitoring of basic indicators of students' functional state $[14,15]$. At the same time, the issues of ways of attracting young people to physical education, improving physical conditions and health conditions remain unsolved.

We assume that physical education classes with the use of athletic gymnastics and mutual learning will improve indicators of health, the physical and mental fitness of young persons.

Aim of Study. The aim of study was to analyze the impact of the mutual learning program of physical education for improvement the physical and mental fitness of students in Ukraine 


\section{Material and Methods}

Participants.

The study involved students of 1-st-3-rd courses aged 17-19 years. By random sampling, we have formed 2 experimental (male, $\mathrm{n}=31$; female, $\mathrm{n}=33$ ) and 2 control groups (male, $n=32$; female, $n=31$ ). Control groups (CG) were engaged in physical education in accordance with the traditional program of physical education, and those in experimental groups (EG) - in the program with the experimental program. This study was approved in advance by protocol proved by Lviv State University of Physical Culture. Each participant voluntarily provided written informed consent before participating.

Research Design.

All students attended obligatory (academic) physical education classes twice a week during the academic year (32 weeks). In both groups (CG and EG), classes were conducted by the same teacher of physical education. Duration of classes in both groups was 90 minutes. In both groups the priority was given to those means of physical education, which were of the highest health effect: athletics, athletic gymnastics, sports games.

The difference in classes in the conditions of forming experiment was in the methods and forms of organization of educational process (Table 1). We have introduced educational-methodical cards with the technique of exercises for mutual training of students, as well as developed tasks for cooperation in subgroups aimed at improving physical fitness of students. The section "Self-monitoring of Health" included a lecture session to introduce students to the measurement of heart rate, blood pressure, filling questionnaires on the state of health.

Students of CG underwent the usual scheme in academic groups and performed the same tasks. Students of EG were engaged in subgroups, which included changing of students, in constant interaction and control of knowledge and skills of each other, in addition, the tasks were separately worked out in microgroups. The subjectsubjective interaction of students was based on the tasks of physical culture, taking into account the unity of the principles of harmonious development of personality and integration of targeted health and educational activities of students. The organizational structure of mutual learning was complex, which combined the group work of students (one teaches many), pair and individual ones. The program contained tasks of varying degrees of complexity for the gradual formation of ability to conduct classes by each student as a teacher; mutual learning of students while doing home tasks (assembling various complexes of exercises); students were involved in mutual analysis

Table 1. The program of mutual learning of students

\begin{tabular}{|c|c|c|}
\hline $\begin{array}{l}\text { Forms of } \\
\text { classes }\end{array}$ & Contents of educational material & Methodological approaches to organization \\
\hline \multirow[t]{2}{*}{ Theoretical } & $\begin{array}{l}\text { Means and methods of physical condition } \\
\text { restoration }\end{array}$ & $\begin{array}{l}\text { Discussion and mutual analysis. Front, frontal- } \\
\text { group method }\end{array}$ \\
\hline & $\begin{array}{l}\text { Presentation of favourite sport. Advertising } \\
\text { for physical education and sports }\end{array}$ & $\begin{array}{l}\text { Interpersonal surveys of students, discussion, } \\
\text { mutual evaluation of material quality. } \\
\text { Presentation (in microgroup of 3-5 people) }\end{array}$ \\
\hline \multirow[t]{5}{*}{ Practical } & $\begin{array}{l}\text { Medical-biological basis of a healthy lifestyle. } \\
\text { Influence of physical exercises on activity of } \\
\text { basic functional systems of the body }\end{array}$ & $\begin{array}{l}\text { Interpersonal control of heart rate of students. } \\
\text { Work in pairs and groups of three }\end{array}$ \\
\hline & $\begin{array}{l}\text { Mutual studying of athletic exercises } \\
\text { performance technique with the use of } \\
\text { educational-methodical cards }\end{array}$ & $\begin{array}{l}\text { Mutual check-up of exercises perfomance. } \\
\text { Group work (3-5 people) }\end{array}$ \\
\hline & $\begin{array}{l}\text { Mastering methods of assessing physical } \\
\text { health. Methods of regulation of emotional } \\
\text { state by physical exercises }\end{array}$ & $\begin{array}{l}\text { Autotraining, relaxation. Mutual analysis and } \\
\text { evaluation by participants of the subgroup ( } 5-7 \\
\text { people) }\end{array}$ \\
\hline & $\begin{array}{l}\text { Development of underdeveloped physical } \\
\text { qualities }\end{array}$ & $\begin{array}{l}\text { Mutual control of exercises performing } \\
\text { (microgroup 5-7 people, depending on the level } \\
\text { of fitness) }\end{array}$ \\
\hline & $\begin{array}{l}\text { Preparation and performance of a game for } \\
\text { the development of certain physical quality }\end{array}$ & $\begin{array}{l}\text { Mutual control and analysis. Work in pairs and } \\
\text { groups of three }\end{array}$ \\
\hline \multirow[t]{4}{*}{ Independent } & $\begin{array}{l}\text { Preparation for classes using educational- } \\
\text { methodical cards on athletics }\end{array}$ & $\begin{array}{l}\text { Selfcontrol, mutual control, work in microgroups } \\
\text { of 3-5 people }\end{array}$ \\
\hline & $\begin{array}{l}\text { Compiling complexes of exercises and } \\
\text { programs for development of physical } \\
\text { qualities }\end{array}$ & $\begin{array}{l}\text { Self and mutual analysis of the subgroup (5-7 } \\
\text { people); brainstorming, round table, mosaic }\end{array}$ \\
\hline & Using and analyzing self-monitoring cards & Self and mutual analysis. Individual method \\
\hline & $\begin{array}{l}\text { Compiling of exercise complexes for } \\
\text { underdeveloped physical qualities }\end{array}$ & $\begin{array}{l}\text { Search for methodical material, compiling } \\
\text { teacher's notes. Work in microgroups (3-5 } \\
\text { people) }\end{array}$ \\
\hline
\end{tabular}


of the exercises. Mutual studying also took place during extracurricular classes. Groups were formed depending on the level of development of individual physical qualities, which were of changing nature for the constant exchange of experience. Under supervision of teacher, students compiled exercise complexes to improve the underdeveloped physical qualities and, according to personally developed programs, engaged in training in their free time.

Students worked in groups of 5-7 people for the development of physical qualities and mastery of physical exercise techniques. At the beginning of the year, students were tested for physical fitness. Formation of groups was based on the levels of physical fitness and physical qualities that were not well developed. Among the members of microgroups, one leader of the group was chosen, who had higher than average or high level of fitness. Leaders of groups on the development of each physical quality changed groups for the harmonious physical development of students. Subsequently, students who showed the growth of physical qualities led the group. As the development of physical qualities among students of one subgroup was uneven, each participant of the experiment was in the role of both the leader and the student. At the end of academic year, physical fitness of students was retested.

Assessment of the somatic health and physical preparadness

The calculation of the Ketle index (body mass, $\mathrm{kg}$ $\times$ height $^{-1}, \mathrm{~cm}$ ), Robinson index (heart rate $\times$ blood pressure $_{\max } \times 100^{-1}$ ), lifetime index (lungs capacity, ml $\times$ mass $\left.^{-1}, \mathrm{~kg}\right)$, strength $(100 \times$ dynamometry of hand, $\mathrm{kg}$ $\times$ body mass $^{-1}, \mathrm{~kg}$ ) and integral assessment of physical health level was carried out according to generally accepted methods [15]. General endurance was assessed by the $3000 \mathrm{~m}$ (male) or $2000 \mathrm{~m}$ (female) running test (scoring in minutes); for evaluating of strength endurance lifting the trunk from the lying position to the sitting one per 1 min was used (scoring in number of times); agility was tested by running $30 \mathrm{~m}$ in a "snake mode" between 5 racks; strength of muscles of the upper shoulder girdle was tested by throw of a medball (result in meters).

\section{Cognitive indices}

The effectiveness of cognitive processes was determined using Schultz-Platonov tables. A person under study was in turn offered five tables, which showed random numbers from 1 to 25 . The task was to look for, show and name the numbers in order of their growth. The sample was repeated using five different tables. The results were determined on three scales - efficiency of processing the tables, speed of figuring out the work and mental stability.

Efficiency of processing (EP) was calculated by the formula:

$$
\mathrm{EP}=(\mathrm{T} 1+\mathrm{T} 2+\mathrm{T} 3+\mathrm{T} 4+\mathrm{T} 5) / 5,
$$

where $\mathrm{Tn}$ is the time of working with a certain table.

Speed of figuring out the work (SF) was calculated by the formula:

$$
\mathrm{SF}=\mathrm{T} 1 / \mathrm{EP}
$$

A score of less than 1.0 was considered as indicator of good figuring out the work; the higher this figure than 1.0 was, the more the person under study needs preparation for the main work.

Mental Stability (MS) was calculated by the formula:

$$
\mathrm{MS}=\mathrm{T} 4 / \mathrm{EP}
$$

A score of less than 1.0 showed good mental health; the higher this indicator was, the worse psychological stability of the person under study.

Statistical Analysis.

The characteristics of subjects were described analyzed by mean value (M), mean square deviation (m). The normal distribution was checked by the Shapiro-Wilk test, for statistical verification of the hypothesis about the probability of differences between the indicators of different groups W-criterion of Wilcoxon was used; the level of significance was set at least to $p<0.05$. Statistic processing was performed using SPSS software.

\section{Results}

There was no difference in the data of functional preparedness of male and female, both in experimental and control groups at the beginning of experiment $(p>$ 0.05 ). The study of weight-height Kettle index gives the right to conclude that male and female of EG and CG do not have significant difference in the indices $(p>0.05)$ (Table 2).

There was an increase in lifetime index of male in EG; it became significantly higher than at the beginning of the experiment at $4.36 \mathrm{ml} / \mathrm{kg}(\mathrm{p}<0.01)$. At the same time, its value at the beginning of the experiment was considered to be lower than the average level, and at the end of experiment - as the average one. Among male of $\mathrm{CG}$, the results of this index were lower than the average level, which was significantly confirmed $(\mathrm{p}<0.05)$. Female of EG have a typical situation $(\mathrm{p}<0.01)$, as well, which indicates an increase in the functional capacity of respiratory system.

Before the experiment the strength index value corresponded to a level below the average, and till the end of the experiment reached an average level. Among female of $C G$, the strength index remained unchanged $(p>0.05)$. Among female of CG no static changes were found at the end of the experiment ( $p>0.05$ ), we clearly observed statistical differences between female of EG and CG $(\mathrm{p}<0.01)$ (Table 3$)$.

After analyzing the value of Robinson index in male of EG and CG at the end of the experiment, a significant difference was found in the indices, as the index of EG students was above the index of CG students at 5.35 units $(\mathrm{p}<0.05)$. In EG female, the functional capacity of cardiovascular system increased at 6.47 units $(\mathrm{p}<0.01)$, in students of $\mathrm{CG}$ - the values of Robinson index were reliably stable $(\mathrm{p}>0.05)$.

At the beginning of the experiment male and female students both of control (CG) and experimental (EG) groups did not show any significant differences regarding the level of physical fitness $(p<0.05)$. Practically in all exercises after the experiment, both male and female from 
Table 2. Dynamics of indices of somatic health of students

\begin{tabular}{|c|c|c|c|c|}
\hline Indices & Groups & $M \pm m$ (before experiment) & $M \pm m$ (after experiment) & pCG \& EG \\
\hline \multicolumn{5}{|l|}{ Male } \\
\hline \multirow{2}{*}{ Kettle index } & CG & $385.43 \pm 31.34$ & $389.56 \pm 32.05^{*}$ & \multirow{2}{*}{$>0.05$} \\
\hline & EG & $389.76 \pm 22.77$ & $390.79 \pm 22.03$ & \\
\hline \multirow{2}{*}{ Lifetime index } & CG & $50.80 \pm 6.34$ & $51.35 \pm 6.18$ & \multirow{2}{*}{$<0.01$} \\
\hline & EG & $52.49 \pm 7.46$ & $56.85 \pm 5.72 \dagger$ & \\
\hline \multirow{2}{*}{ Strength } & CG & $62.42 \pm 10.35$ & $63.70 \pm 10.01$ & \multirow{2}{*}{$<0.05$} \\
\hline & EG & $61.39 \pm 9.49$ & $67.99 \pm 6.31 \dagger$ & \\
\hline \multirow{2}{*}{ Robinson index } & CG & $90.94 \pm 10.97$ & $87.56 \pm 10.32 *$ & \multirow{2}{*}{$<0.05$} \\
\hline & EG & $93.50 \pm 10.53$ & $82.21 \pm 8.22 \dagger$ & \\
\hline \multicolumn{5}{|l|}{ Female } \\
\hline \multirow{2}{*}{ Kettle index } & CG & $367.57 \pm 17.66$ & $367.44 \pm 17.74$ & \multirow{2}{*}{$>0.05$} \\
\hline & EG & $358.07 \pm 21.65$ & $360.81 \pm 20.83$ & \\
\hline \multirow{2}{*}{ Lifetime index } & CG & $42.05 \pm 3.57$ & $43.97 \pm 4.28^{*}$ & \multirow{2}{*}{$<0.01$} \\
\hline & EG & $42.81 \pm 5.57$ & $47.46 \pm 4.58+$ & \\
\hline \multirow{2}{*}{ Strength } & CG & $39.53 \pm 5.61$ & $41.56 \pm 5.75$ & \multirow{2}{*}{$<0.01$} \\
\hline & EG & $41.15 \pm 6.55$ & $47.46 \pm 6.58 \dagger$ & \\
\hline \multirow{2}{*}{ Robinson index } & CG & $87.78 \pm 9.11$ & $86.17 \pm 8.53$ & \multirow{2}{*}{$<0.05$} \\
\hline & EG & $87.81 \pm 10.18$ & $81.34 \pm 8.98^{+}$ & \\
\hline
\end{tabular}

Note. ${ }^{*} p<0.05,+p<0.01$

the EG experienced significant statistical positive changes (Table 3).

The growth of the results among female of EG was set in lifting the trunk from the lying position to the sitting one at $9.3 \%$, and throw of medball from the sitting position with two hands from behind the head $12.2 \%$, among male of EG in lifting the trunk from the lying position to the sitting one at $10.1 \%$. Insignificant statistical changes occurred among female of EG in exercises: running "in

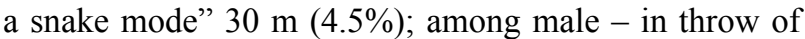
medball from the sitting position with two hands from behind the head (4.4\%). The result of running at $3000 \mathrm{~m}$ among EG male improved by $3.8 \%$ (14 s), while those of $\mathrm{CG}$ improved at $0.7 \%(10 \mathrm{~s})$. Among female of EG it has been noticed an increase in the results of running at 2000 $\mathrm{m}$ by $3.1 \%$.

The results of throw of medball from the sitting position with two hands from behind the head among EG male increased by $4.4 \%(31 \mathrm{~cm})(\mathrm{p}<0.001)$, while EG female improved the result by $14.3 \%(53 \mathrm{~cm})(\mathrm{p}<0.001)$. Significant differences were detected between female of both groups $(\mathrm{p}<0.001)$.

Among EG male, the overall level of fitness increased from an average level with $2.81 \pm 0.70$ to above the average one with $3.77 \pm 0.88$ points $(\mathrm{p}<0.001)$. Among EG female level of fitness increased from $2.61 \pm 0.79$ to $3.58 \pm 0.79$ points, which corresponds to the average level $(\mathrm{p}=0.001)$. There were no statistically significant changes in CG male and female.

After the experiment, positive changes in cognitive parameters were observed both in female and male of EG $(p<0.05)$ (Table 3$)$. The efficiency of processing the tables among EG male at the beginning of the experiment was at satisfactory level, the average time for processing each table was within $51.85 \pm 18.95 \mathrm{~s}$. After the pedagogical experiment, the efficiency of processing was $41.89 \pm 8.40$ $\mathrm{s}(\mathrm{p}<0.05)$, which corresponds to sufficient level.

At the end of the experiment among CG male we have also revealed an increase in the efficiency of processing the tables $(p<0.05)$. Nevertheless, there were significant differences between EG and CG students: male of EG at $7.88 \mathrm{~s}$ faster processed the tables than those of CG $(\mathrm{p}<$ 0.05).

Analyzing the tendencies of spatial distribution and amount of attention among EG female, we have observed improvement in the efficiency of processing the tables at $9.26 \mathrm{~s}(\mathrm{p}<0.01)$, in $\mathrm{CG}$ - significant differences were not found $(\mathrm{p}>0.05)$. The difference in rates between female CG and EG after the experiment was $8.51(\mathrm{p}<0.001)$.

Speed of figuring out the work at the beginning of the experiment among female and male both in EG and CG was low $(>1.0)$. Among EG male results in the course of experiment increased by $0.12 \mathrm{~s}(\mathrm{p} \leq 0.01)$, in $\mathrm{CG}-$ no differences were found. Among EG female we have revealed a statistically significant improvement in the speed of figuring out the work (at the beginning of the experiment the result was $1.07 \pm 0.18$, and at the end $0.97 \pm 0.10, \mathrm{p}<0.01)$. Among $\mathrm{CG}$ female, the results were significantly stable $(\mathrm{p}>0.05)$ (Table 4$)$. After the experiment among male of $\mathrm{EG}$, the value of mental 
Table 3. Changes in physical fitness and cognitive indices of students

\begin{tabular}{|c|c|c|c|c|c|}
\hline Qualities & Groups & $\begin{array}{l}M \pm m \text { (before } \\
\text { experiment) }\end{array}$ & $\begin{array}{l}M \pm m \text { (after } \\
\text { experiment) }\end{array}$ & $p$ & $\begin{array}{l}\text { pCG \& } \\
\text { EG }\end{array}$ \\
\hline \multicolumn{6}{|l|}{ Physical fitness } \\
\hline \multicolumn{6}{|l|}{ Male } \\
\hline \multirow[t]{2}{*}{ General endurance } & CG & $14.30 \pm 1.04$ & $14.20 \pm 0.91$ & $>0.05$ & $<0.05$ \\
\hline & EG & $14.10 \pm 0.81$ & $13.56 \pm 0.67$ & $<0.05$ & \\
\hline \multirow[t]{2}{*}{ Strength endurance } & CG & $40.63 \pm 4.53$ & $43.22 \pm 4.11$ & $<0.05$ & $<0.01$ \\
\hline & EG & $41.94 \pm 4.10$ & $46.68 \pm 4.54$ & $<0.001$ & \\
\hline \multirow{2}{*}{$\begin{array}{l}\text { Strength of muscles of the upper } \\
\text { shoulder girdle }\end{array}$} & CG & $6.96 \pm 0.47$ & $7.01 \pm 0.45$ & $>0.05$ & $<0.05$ \\
\hline & EG & $7.00 \pm 0.54$ & $7.31 \pm 0.53$ & $<0.001$ & \\
\hline \multirow[t]{2}{*}{ Agility } & CG & $5.15 \pm 0.14$ & $5.09 \pm 0.16$ & $>0.05$ & $<0.01$ \\
\hline & EG & $5.11 \pm 0.15$ & $4.95 \pm 0.14$ & $<0.001$ & \\
\hline \multicolumn{6}{|l|}{ Female } \\
\hline \multirow[t]{2}{*}{ General endurance } & CG & $11.53 \pm 0.81$ & $11.51 \pm 0.71$ & $>0.05$ & $<0.05$ \\
\hline & EG & $11.52 \pm 0.67$ & $11.16 \pm 0.53$ & $<0.05$ & \\
\hline \multirow[t]{2}{*}{ Strength endurance } & CG & $38.03 \pm 5.08$ & $40.26 \pm 3.74$ & $<0.05$ & $<0.05$ \\
\hline & EG & $38.70 \pm 4.46$ & $42.30 \pm 2.72$ & $<0.001$ & \\
\hline \multirow{2}{*}{$\begin{array}{l}\text { Strength of muscles of the upper } \\
\text { shoulder girdle }\end{array}$} & CG & $5.43 \pm 0.66$ & $5.54 \pm 0.66$ & $>0.05$ & $<0.01$ \\
\hline & EG & $5.31 \pm 0.53$ & $5.96 \pm 0.40$ & $<0.001$ & \\
\hline \multirow[t]{2}{*}{ Agility } & CG & $6.21 \pm 0.29$ & $6.10 \pm 0.23$ & $<0.05$ & $<0.05$ \\
\hline & EG & $6.26 \pm 0.28$ & $5.98 \pm 0.26$ & $<0.001$ & \\
\hline \multicolumn{6}{|l|}{ Cognitive indices } \\
\hline \multicolumn{6}{|l|}{ Male } \\
\hline \multirow{2}{*}{$\begin{array}{l}\text { Efficiency of processing the } \\
\text { tables }\end{array}$} & CG & $51.61 \pm 17.61$ & $49.77 \pm 19.22$ & $<0.05$ & $<0.05$ \\
\hline & EG & $51.85 \pm 18.95$ & $41.89 \pm 8.40$ & $<0.05$ & \\
\hline \multirow[t]{2}{*}{ Speed of figuring out the work } & CG & $1.02 \pm 0.25$ & $1.01 \pm 0.29$ & $>0.05$ & $>0.05$ \\
\hline & EG & $1.05 \pm 0.25$ & $0.93 \pm 0.18$ & $\leq 0.01$ & \\
\hline \multirow[t]{2}{*}{ Mental stability } & CG & $1.04 \pm 0.17$ & $1.07 \pm 0.17$ & $>0.05$ & $<0.05$ \\
\hline & EG & $1.09 \pm 0.20$ & $0.99 \pm 0.13$ & $<0.05$ & \\
\hline \multicolumn{6}{|l|}{ Female } \\
\hline \multirow{2}{*}{$\begin{array}{l}\text { Efficiency of processing the } \\
\text { tables }\end{array}$} & CG & $50.09 \pm 9.78$ & $50.01 \pm 11.05$ & $>0.05$ & $<0.001$ \\
\hline & EG & $50.76 \pm 8.52$ & $41.50 \pm 6.55$ & $<0.01$ & \\
\hline \multirow[t]{2}{*}{ Speed of figuring out the work } & CG & $1.09 \pm 0.25$ & $1.10 \pm 0.23$ & $>0.05$ & $<0.01$ \\
\hline & EG & $1.07 \pm 0.18$ & $0.97 \pm 0.15$ & $<0.01$ & \\
\hline \multirow[t]{2}{*}{ Mental stability } & CG & $1.03 \pm 0.16$ & $1.09 \pm 0.17$ & $>0.05$ & $<0.01$ \\
\hline & EG & $1.06 \pm 0.11$ & $0.97 \pm 0.10$ & $<0.001$ & \\
\hline
\end{tabular}

stability increased to $0.99 \pm 0.13(\mathrm{p}<0.05)$, and in $\mathrm{CG}-$ decreased to $1.07 \pm 0.17$, but statistically, changes in CG were not confirmed $(\mathrm{p}>0.05)$.

\section{Discussion}

An assessment of the functional state of body and its reserve capacities is important for determining the effectiveness of physical education classes [16, 17]. Good functional state can be considered as a prerequisite for high physical working efficiency and potential ability of the body to adapt to physical activity $[10,18]$.

The Kettle index of CG and EG students is on the average level of completeness for both female and male [8]. However, an individual analysis of the results showed that in $11.3 \%$ of male there is a shortage of body mass, and $3.8 \%$ are overweight, whereas in female the figures 
are $14.2 \%$ and $10.6 \%$, respectively.

The level of musculoskeletal system functions reserve of female in EG is estimated to be lower than the average, an increase in the strength index was noted $(\mathrm{p}<0.01)$, but the initial data were too low. According to Robinson index (in a state of rest), we characterized reserves criteria and economization of cardiovascular system functions. Reduction of this index indicates an improvement in the work of the abovementioned system. Characteristics of the functional capacity of cardiovascular system of EG male (Robinson index) was at a level higher than the average, in CG male- indices also significantly improved $(\mathrm{p}<0.05)$ and corresponded to the average level [8].

As a result of the experiment, the values of this index for EG female were higher than the average level, and in CG those values were the average. The study of the dynamics of Robinson index results shows that due to the implementation of aerobic exercises, we observe the improvement of the cardiovascular system both in male and female of EG $[18,19]$.

After the experiment, positive progress was observed among students of EG viewing the level of physical fitness. The progress of CG students did not have such a distinctive character and was the result of natural human development [20]. Improvement of physical fitness indices among students of EG was achieved, first of all, due to the use of means and methodical techniques aimed at attracting students to self-study and mutual studying during academic classes on physical education. They included compilation, conducting and performing of exercise complexes, analysis of exercise techniques and adjustment of loading according to heart rate figures. Also, during independent performing of exercise complexes while extracurricular forms of physical education, which contributed to the deepening of knowledge, abilities, skills, positive changes in motivation to regular physical activity, and thus increase in the volume of motor activity of students.
Strength indices have increased among students due to the use of exercises with weights, overcoming resistance of the partner, with equipment and on gymnastic devices. Among male of EG, increase in results of strength endurance (in lifting the trunk from the lying position to the sitting one) increased by $11.3 \%$ from the average to above the average, and among EG female - 9.3\% from below the average to the average. Such increase can be explained by the fact that strength is the fastest growing quality, but if one does not maintain the level achieved by systematic exercising, it will soon be lost [21].

The results of the experiment confirm the effectiveness of the program in terms of improving cognitive indices. After the pedagogical experiment, a positive growth of indices was established, in particular, the efficiency of processing corresponded to sufficient level.

\section{Conclusions}

The results suggest that experimental program of mutual learning can help to improve the fitness level and adaptation abilities of an organism. The program had a significant impact on the indicators of the cardiovascular system and mental abilities of students of both gender. These findings also indicate that such pedagogical program with the special emphasis on mutual learning could serve as an effective health-preserving means of physical education.

\section{Funding}

This research received no external funding.

\section{Acknowledgments}

We acknowledge the time and effort of all participants in this study.

\section{Conflicts of Interest}

The authors declare no conflict of interest.

\section{References}

1. Pavlova I, Vynogradskyi B, Kurchaba T, Zikrach D. Influence of leisure-time physical activity on quality of life of Ukrainian students. J Phys Educ Sport. 2017;17(3):1037-42. https://doi.org/10.1123/pes.15.3.257

2. Fedewa AL, Ahn S. The Effects of Physical Activity and Physical Fitness on Children's Achievement and Cognitive Outcomes. Res $Q$ Exerc Sport. 2011;82(3):521-35. https://doi.org/10.1080/02701367.2011.10599785

3. Pate RR, Ross R, Dowda M, Trost SG, Sirard JR. Validation of a 3-Day Physical Activity Recall Instrument in Female Youth. Pediatr Exerc Sci. 2003;15(3):257-65. https://doi.org/10.1123/pes.15.3.257

4. Haskell WL, Lee I-M, Pate RR, Powell KE, Blair SN, Franklin BA, et al. Physical activity and public health: updated recommendation for adults from the American College of Sports Medicine and the American Heart Association. Med Sci Sports Exerc. 2007;39(8):1423-34. https://doi.org/10.1249/mss.0b013e3180616b27

5. Thomas SB, Fine MJ, Ibrahim SA. Health disparities: the importance of culture and health communication. Am J Public Health. 2004;94(12):2050. https://doi.org/10.2105/AJPH.94.12.2050

6. Häyry M. Public health and human values. $J$ Med Ethics. 2006;32(9):519-21. https://doi.org/10.1136/jme.2005.014258

7. Bucksch J. Physical activity of moderate intensity in leisure time and the risk of all cause mortality. $B r \quad J$ Sports Med. 2005;39(9):632-8. https://doi.org/10.1136/bjsm.2004.015768

8. Khaw K-T, Jakes R, Bingham S, Welch A, Luben R, Day $\mathrm{N}$, et al. Work and leisure time physical activity assessed using a simple, pragmatic, validated questionnaire and incident cardiovascular disease and all-cause mortality in men and women: The European Prospective Investigation into Cancer in Norfolk prospective population study. Int $J$ Epidemiol. 2006;35(4):1034-43. https://doi.org/10.1093/ije/dy1079

9. Krutsevych T. Methods of study of individual health of children and adolescents in the process of physical education. Kyyiv: Olympic literature; 1999.

10.BlairSN, ChengY, ScottHolderJ.Isphysicalactivityorphysical 
fitness more important in defining health benefits?: Medicine and Science in Sports and Exercise, 2001;33:S379-99. https://doi.org/10.1097/00005768-200106001-00007

11.Donnelly JE, Hillman CH, Castelli D, Etnier JL, Lee $\mathrm{S}$, Tomporowski $\mathrm{P}$, et al. Physical Activity, Fitness, Cognitive Function, and Academic Achievement in Children: A Systematic Review. Medicine \& Science in Sports \& Exercise, 2016;48:1197-222. https://doi.org/10.1249/MSS.0000000000000901

12.Mandic S, Wilson H, Clark-Grill M, O'neill D, Mandic S. A Physical Activity Learning Module Improves Medical Students' Skills and Confidence for Advising Patients about Physical Activity. J Sport Sci Med. 2018;7:31-8. https://doi.org/10.26773/mjssm.180304

13. Vashchuk L, Dedeliuk N, Roda O, Kalytka S, Demianchuk O, Matskevych N, et al. The realization of the individual fitness programs in the physical education of high schoolgirls. Phys Act Rev. 2018;6:144-50. https://doi.org/10.16926/par.2018.06.19

14.Donnelly JE, Hillman CH, Castelli D, Etnier JL, Lee S, Tomporowski P, et al. Physical Activity, Fitness, Cognitive Function, andAcademicAchievementinChildren:ASystematic Review. Med Sci Sports Exerc. 2016;48(6):1197-222. https://doi.org/10.1249/MSS.0000000000000901

15.Pavlova I, Bodnar I, Vitos J. The role of karate in preparing boys for school education. Phys Act Rev. 2018;6:54-63. https://doi.org/10.16926/par.2018.06.08

16.Committee on Physical Activity and Physical Education, in the School Environment, Food and Nutrition Board.
Educating the student body: taking physical activity and physical education to school. Kohl III HW, Cook HD, editors. Washington, D.C.: The National Academies Press; 2012.

17.Tomás MT, Galán-Mercant A, Carnero EA, Fernandes B. Functional Capacity and Levels of Physical Activity in Aging: A 3-Year Follow-up. Frontiers in Medicine, 2018;4:244. https://doi.org/10.3389/fmed.2017.00244

18.Amsterdam EA, Mason DT. Exercise testing and indirect assessment of myocardial oxygen consumption in evaluation of angina pectoris. Cardiology. 1977;62(3):174-89. https://doi.org/10.1159/000169852

19. Hasselstrøm H, Hansen SE, Froberg K, Andersen LB. Physical Fitness and Physical Activity During Adolescence as Predictors of Cardiovascular Disease Risk in Young Adulthood. Danish Youth and Sports Study. An Eight-Year Follow-Up Study. Int J Sports Med. 2002;23(S1):27-31. https://doi.org/10.1055/s-2002-28458

20.Kemper HCG, de Vente W, van Mechelen W, Twisk JWR. Adolescent motor skill and performance: Is physical activity in adolescence related to adult physical fitness? Am J Hum Biol. 2001;13(2):180-9. h t t p s : / / d o i.org / 10 . $10002 / 1520$ 6300(200102/03)13:2<180::AID-AJHB1027>3.0.CO;2-R

21.Willis LH, Slentz CA, Bateman LA, Shields AT, Piner $\mathrm{LW}$, Bales CW, et al. Effects of aerobic and/or resistance training on body mass and fat mass in overweight or obese adults. $J$ Appl Physiol. 2012;113(12):1831-7. https://doi.org/10.1152/japplphysiol.01370.2011

\section{Information about the authors:}

Bodnar I.; http://orcid.org/0000-0002-7083-6271; j.wasik@ujd.edu.pl; Theory and Methods of Physical Culture Department, Lviv State University of Physical Culture, Ukraine; 11 Kostyushka Street, Lviv, 79000, Ukraine.

Pavlova lu.; http://orcid.org/0000-0002-8111-4469; j.wasik@ujd.edu.pl; Theory and Methods of Physical Culture Department, Lviv State University of Physical Culture, Ukraine; 11 Kostyushka Street, Lviv, 79000, Ukraine.

Dukh T.; http://orcid.org/0000-0002-2401-9203; j.wasik@ujd.edu.pl; Athletics Department, Lviv State University of Physical Culture, Ukraine; 11 Kostyushka Street, Lviv, 79000, Ukraine.

Wąsik J.; (Corresponding Author); http://orcid.org/0000-0002-6285-7283; j.wasik@ujd.edu.pl; Institute of Physical Education, Tourism and Physiotherapy, Jan Długosz University in Czestochowa, Poland; ul. Waszyngtona 4/8, 42-200 Częstochowa, Poland.

Mosler D.; http://orcid.org/0000-0002-8794-2994; j.wasik@ujd.edu.pl; Institute of Physical Education, Tourism and Physiotherapy, Jan Długosz University in Czestochowa, Poland; ul. Waszyngtona 4/8, 42-200 Częstochowa, Poland.

Svyshch Y.; http://orcid.org/0000-0002-1573-8599; j.wasik@ujd.edu.pl; Athletics Department, Lviv State University of Physical Culture, Ukraine; 11 Kostyushka Street, Lviv, 79000, Ukraine.

\section{Cite this article as:}

Bodnar I, Pavlova lu, Dukh T, Wąsik J, Mosler D, Svyshch Y. Effects of mutual learning in physical education to improve health indicators of Ukrainian students. Physical education of students, 2019;23(5):229-235. https://doi.org/10.15561/20755279.2019.0503

This is an Open Access article distributed under the terms of the Creative Commons Attribution License, which permits unrestricted use, distribution, and reproduction in any medium, provided the original work is properly cited http://creativecommons.org/licenses/by/4.0/deed.en

Received: 12.09 .2019

Accepted: 17.10.2019; Published: 26.10.2019 